\title{
Risk of cardiovascular disease with lipoprotein(a) in familial hypercholesterolemia: a review
}

Jun Watanabe, Masato Hamasaki, Kazuhiko Kotani

Division of Community and Family Medicine, Jichi Medical University, Shimotsuke-City, Japan

Submitted: 7 June 2020

Accepted: 8 June 2020

Arch Med Sci Atheroscler Dis 2020; 5: e148-e152

DOI: https://doi.org/10.5114/amsad.2020.97105

Copyright $\odot 2020$ Termedia \& Banach

\section{Abstract}

Introduction: Lipoprotein(a) (Lp[a]) is a risk factor of cardiovascular disease (CVD). Familial hypercholesterolemia (FH), which exhibits high low-density lipoprotein cholesterol (LDL-C) levels, is a risk factor of CVD. The relationship of $L p(a)$ with CVD has been characterized in populations specific to $\mathrm{FH}$.

Material and methods: Studies reporting on the relationship of $L p(a)$ with CVD among FH subjects via PubMed up to 2020 were reviewed.

Results: Eight studies were identified as eligible. In the meta-analyses, a high $L p(a)$ level was significantly and predictively associated with CVD compared to a low $\mathrm{Lp}(\mathrm{a})$ level in 2 cross-sectional studies (odds ratio $=2.57$; 95\% confidence interval (CI): 1.16-5.73) and 6 cohort studies (risk/hazard ratio $=1.91 ; 95 \% \mathrm{Cl}: 1.50-2.43)$. The totally integrated relative risk of these studies was $1.97(95 \% \mathrm{Cl}: 1.57-2.46)$.

Conclusions: FH subjects with high Lp(a) levels can have a high CVD risk, and besides LDL-C, attention should be paid to Lp(a) levels in FH subjects.

Key words: apoprotein(a), coronary artery disease, coronary heart disease.

\section{Introduction}

Lipoprotein(a) (Lp[a]) is a low-density lipoprotein (LDL)-like particle that binds to the protein apoprotein(a) (this protein has a structure homologous to plasminogen) [1]. Due to the unique features of $L p(a)$ (i.e. thrombogenic and atherogenic properties) [2], Lp(a) is recognized as a risk factor of cardiovascular disease (CVD) [3-6]. Of interest, the blood Lp(a) levels are largely determined by genetic factors [7].

Familial hypercholesterolemia (FH) is an autosomal dominant genetic disease [8]. The main causative genes are related to LDL clearance by the $L D L$ receptor (LDLR), leading to high blood levels of $L D L$ cholesterol (LDL-C) [9]. FH is recognized as a risk factor of CVD [10].

A combinatory relationship between LDL-C and Lp(a) for CVD has been previously suggested, although the previous studies did not specifically examine FH subjects $[11,12]$. A few studies also show that FH subjects with high Lp(a) levels had an increased risk of CVD, but these studies were conducted in somewhat specific settings (e.g. in the coronary care unit at a single hospital [13] or during a cascade test screening for family members of FH subjects [14]). As such, the relationship of Lp(a) with CVD outcomes has yet to be characterized in a population limited to $\mathrm{FH}$.

\author{
Corresponding author: \\ Prof. Kazuhiko Kotani \\ Division of Community \\ and Family Medicine \\ Jichi Medical University \\ 3311-1 Yakushiji \\ Shimotsuke-City, \\ Japan 329-0498 \\ Phone: +81 285587394 \\ E-mail: kazukotani@jichi.ac.jp
}


Whether or not the impact of $L p(a)$ on CVD can be modulated in $\mathrm{FH}$, a condition of high LDL-C levels, is still of interest. In the current study, we therefore conducted a meta-analysis of available studies to determine the relationship of $L p(a)$ with CVD outcomes in FH subjects.

\section{Material and methods}

Candidate articles for this study were searched using PubMed up to April 25, 2020 using the following keywords: "familial hypercholesterolemia" AND ("lipoprotein(a) (Title/Abstract)" AND "cardiovascular disease (Title/Abstract)" AND risk NOT review (Publication type)). Cardiovascular disease was defined as coronary heart disease and stroke (cerebrovascular disease). Studies that focused on the relationship of $L p(a)$ with CVD in $\mathrm{FH}$ were included. Studies written in a language other than English and for a non-adult population were excluded. The title and abstract of all studies identified through the search were screened. In addition, the reference lists of the retrieved articles were searched for further identification of relevant studies.

\section{Statistical analysis}

The studies reporting the CVD risk by Lp(a), as odds ratio (OR) and risk/hazard ratio (HR) with 95\% confidence interval $(\mathrm{Cl})$, were finally collected. When multivariate estimates were reported, the maximally adjusted estimates were extracted. The OR in cross-sectional studies and the RR and $H R$ in cohort studies were used to assess the risk of CVD by high Lp(a) levels compared to low Lp(a) levels. Random-effects meta-analyses for CVD outcomes were performed in the Review Manager software program (RevMan ver. 5.3) using the generic inverse variance method. The results were expressed as the OR and $\mathrm{HR}$ with $95 \% \mathrm{Cls}$, and heterogeneity was assessed using $P$ statistics. In addition, when the $\mathrm{OR}$ and HR were considered approximately equivalent as relative risks, an integrated meta-analysis was performed.

\section{Results}

Figure 1 shows the flow for selecting articles that reported the relationship of $L p(a)$ with CVD outcomes. Of the 43 initially identified articles, 25 that did not focus on this relationship were excluded. After reviewing the full text and the reference lists of all retrieved articles, eight articles [15-22] met the criteria. The 8 studies $(8,378$ participants and 1,458 CVD outcomes) included 2 cross-sectional studies and 6 cohort studies.

Table I shows a summary of the association of Lp(a) with CVD in the two cross-sectional studies. As shown in Figure 2, the two studies found high $\mathrm{Lp}(\mathrm{a})$ levels to be positively associated with CVD compared to low $\mathrm{Lp}(\mathrm{a})$ levels $(\mathrm{OR}=2.57 ; 95 \% \mathrm{Cl}$ : $\left.1.16-5.73 ; I^{2}=49 \%\right)$. A summary of the prediction of Lp(a) on CVD is shown in Table II in six cohort studies. High L $p(a)$ levels predicted CVD compared to low $\mathrm{Lp}(\mathrm{a})$ levels with $\mathrm{HR}(1.91 ; 95 \% \mathrm{Cl}: 1.50-$ $2.43 ; I^{2}=59 \%$; Figure 3 ). In addition, the integrated relative risk of all studies was $1.97(95 \% \mathrm{Cl}$ : $1.57-2.46 ; P^{2}=53 \%$ ).

\section{Discussion}

The current meta-analysis reviewed the relationship of Lp(a) with CVD outcomes in $\mathrm{FH}$ sub-

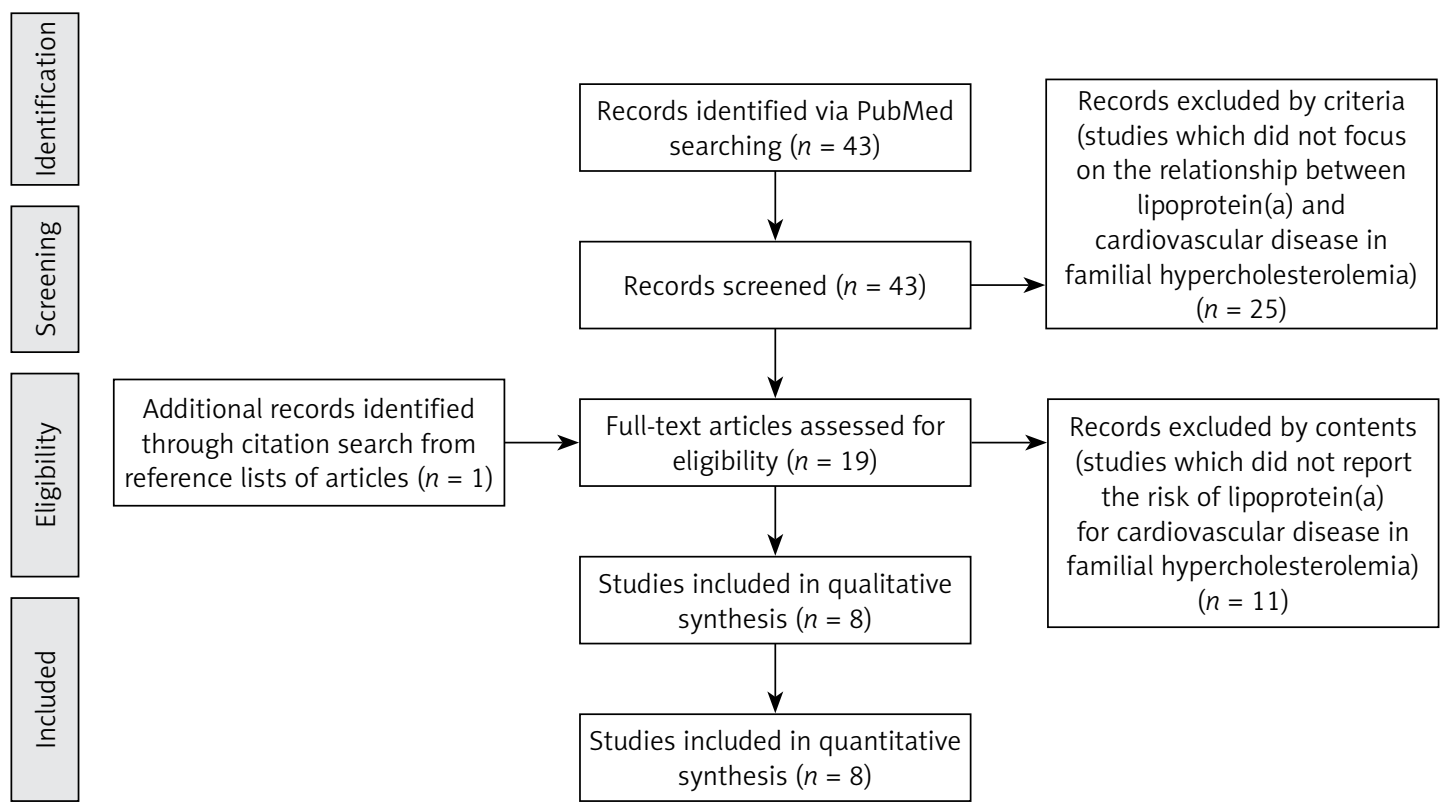

Figure 1. Flow diagram of study selection 
Table I. The association of $L p(a)$ with CVD by odds ratio in two cross-sectional studies

\begin{tabular}{|lcccccc|}
\hline $\begin{array}{l}\text { Authors } \\
\text { [ref. no.] }\end{array}$ & Year & $\begin{array}{c}\text { Subjects ( } n \text { ) } \\
\text { CVD/non-CVD }\end{array}$ & $\begin{array}{c}\text { Age [years] } \\
\text { CVD/non-CVD }\end{array}$ & Confounders & $\begin{array}{c}\text { Cut-off level } \\
\text { of Lp(a) }\end{array}$ & OR (95\% Cl) \\
\hline Chan [15] & 2015 & $64 / 326$ & $57 / 43$ & - & $50 \mathrm{mg} / \mathrm{dl}$ & $1.90(1.09-3.31)$ \\
\hline Sun [16] & 2018 & $61 / 87$ & $49 / 45$ & $\begin{array}{c}\text { Age, sex, smoking, } \\
\text { hypertension, diabetes } \\
\text { mellitus, body mass } \\
\text { index, high-density } \\
\text { lipoprotein cholesterol, } \\
\text { statin, family history of } \\
\text { CVD }\end{array}$ & $60 \mathrm{mg} / \mathrm{dl}$ & $4.46(1.55-12.83)$ \\
\hline Cl-confidence interval, CVD - cardiovascular disease, Lp (a) - lipoprotein(a), n- number, OR - odds ratio, ref. no. - reference number.
\end{tabular}

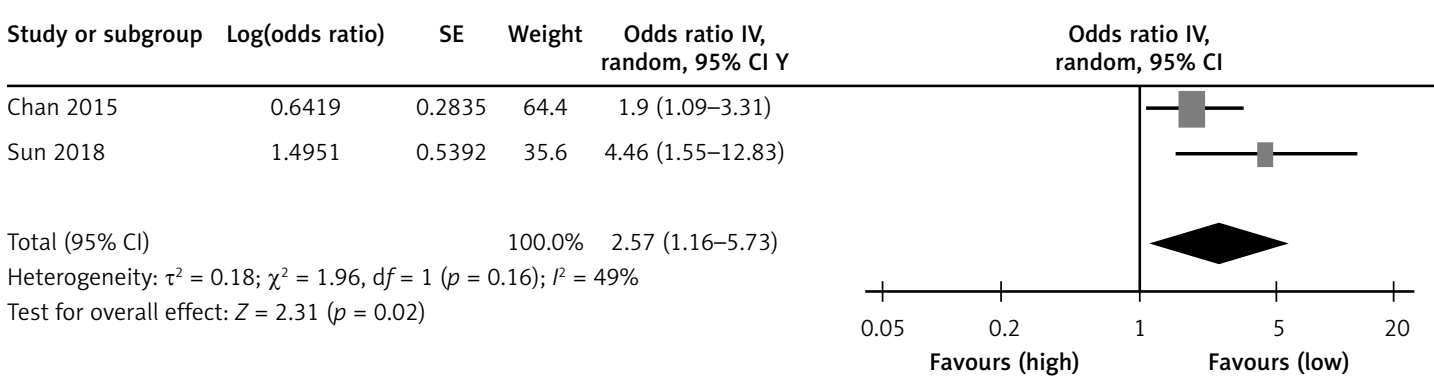

Figure 2. Forest plot based on a meta-analysis of the odds ratio in the association of lipoprotein(a) with cardiovascular disease in cross-sectional studies

Table II. The prediction of $L p(a)$ for CVD by risk ratio in three cohort studies

\begin{tabular}{|c|c|c|c|c|c|c|}
\hline $\begin{array}{l}\text { Authors } \\
\text { [ref. no.] }\end{array}$ & Year & $\begin{array}{c}\text { Subjects } \\
\text { (number) } \\
\text { CVD/non-CVD }\end{array}$ & $\begin{array}{c}\text { Age [years] } \\
\text { CVD/non-CVD }\end{array}$ & Confounders & $\begin{array}{l}\text { Cut-off level } \\
\text { of } \operatorname{Lp}(a)\end{array}$ & HR $(95 \% \mathrm{Cl})$ \\
\hline Jansen [17] & 2004 & $782 / 1618$ & $50.4 / 42.0$ & $\begin{array}{c}\text { Sex, smoking, } \\
\text { hypertension, diabetes } \\
\text { mellitus, body mass index, } \\
\text { high-density lipoprotein } \\
\text { cholesterol, triglyceride, } \\
\text { homocysteine }\end{array}$ & $30 \mathrm{mg} / \mathrm{dl}$ & $1.50(1.20-1.79)$ \\
\hline $\begin{array}{l}\text { Holmes } \\
{[18]}\end{array}$ & 2005 & $61 / 327$ & 53.0 & $\begin{array}{c}\text { Sex, smoking, } \\
\text { hypertension, total } \\
\text { cholesterol/high-density } \\
\text { lipoprotein cholesterol, } \\
\text { low-density lipoprotein } \\
\text { cholesterol }\end{array}$ & $56 \mathrm{mg} / \mathrm{dl}$ & $2.59(1.53-4.39)$ \\
\hline Allard [19] & 2014 & $74 / 221$ & $67.7 / 58.0$ & $\begin{array}{l}\text { Sex, smoking, diabetes } \\
\text { mellitus, body mass index, } \\
\text { high-density lipoprotein } \\
\text { cholesterol, low-density } \\
\text { lipoprotein cholesterol, } \\
\text { triglyceride, family history } \\
\text { of premature CVD }\end{array}$ & $60 \mathrm{mg} / \mathrm{dl}$ & $1.8(1.1-2.9)$ \\
\hline Alonso [20] & 2014 & $247 / 1713$ & 44.4 & - & $50 \mathrm{mg} / \mathrm{dl}$ & $2.07(1.64-2.61)$ \\
\hline $\begin{array}{l}\text { Pérez De } \\
\text { Isla [21] }\end{array}$ & 2015 & $122 / 185$ & 44.5 & $\begin{array}{c}\text { Age, sex, smoking, } \\
\text { hypertension, diabetes } \\
\text { mellitus, waist } \\
\text { circumference, body } \\
\text { mass index, high-density } \\
\text { lipoprotein cholesterol, } \\
\text { low-density lipoprotein } \\
\text { cholesterol, triglyceride, } \\
\text { history of CVD, statin }\end{array}$ & $50 \mathrm{mg} / \mathrm{dl}$ & $1.52(1.05-2.21)$ \\
\hline Cao [22] & 2019 & $35 / 358$ & $50.3 / 48.5$ & $\begin{array}{l}\text { triglyceride, total } \\
\text { cholesterol }\end{array}$ & $52.0 \mathrm{mg} / \mathrm{dl}$ & $6.96(2.24-9.32)$ \\
\hline
\end{tabular}




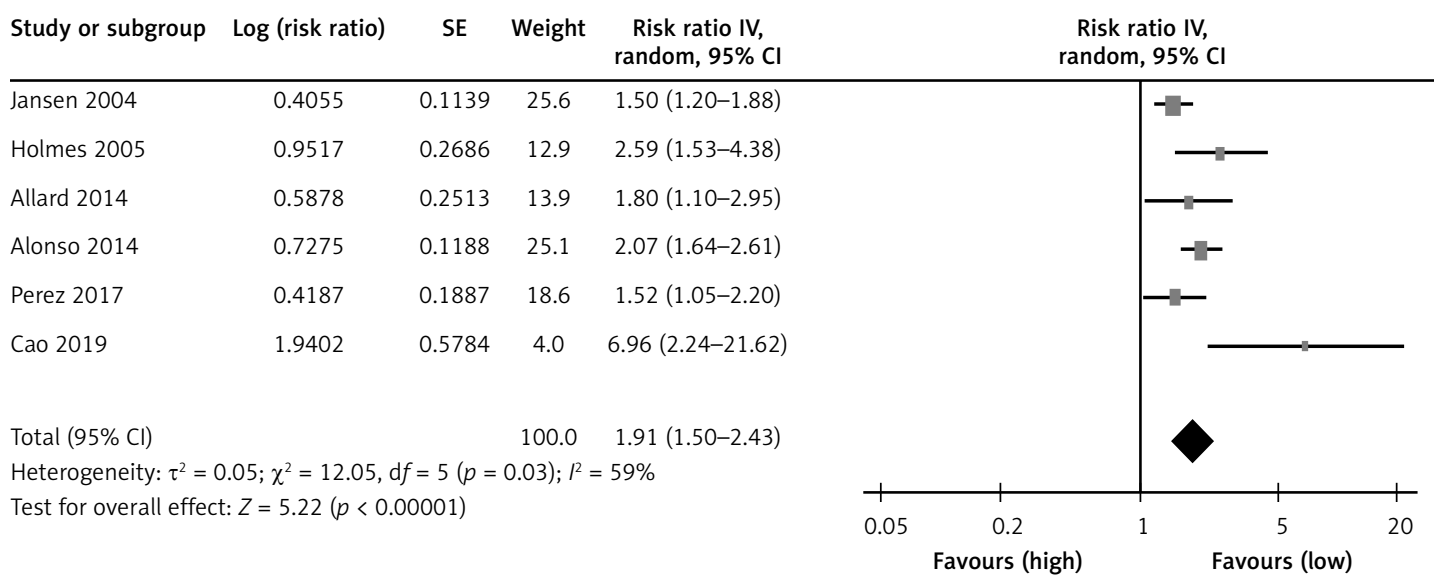

Figure 3. Forest plot based on a meta-analysis of the risk/hazard ratio in the association of lipoprotein(a) with cardiovascular disease in cohort studies

jects. The findings from the meta-analysis showed that a high Lp(a) level remained a risk factor for CVD among FH subjects.

This meta-analysis revealed the risk of CVD as an OR of 2.57 and HR of 1.91, as well as an integrated relative risk of 1.97 . In an earlier metaanalysis of the relationship of $L p(a)$ with CVD in a general population, an RR of 1.57 for CVD was demonstrated when the group with the high $L p(a)$ level was compared to that with the low level [5]. In a cohort study of hypercholesterolemic subjects with LDL-C of $\geq 3.1 \mathrm{mmol} / \mathrm{l}(121 \mathrm{mg} / \mathrm{dl})$, the HR of 1.64 for CVD was demonstrated when the group with a high $\operatorname{Lp}(\mathrm{a})$ level ( $\geq 44 \mathrm{mg} / \mathrm{dl}$ ) was compared to that with a low level [11]. The risk for CVD with Lp(a) among FH subjects, as observed in the current meta-analysis, seemed to be similar to or slightly high relative to the risks described for these data $[5,11]$.

The threshold of Lp(a) causing CVD may be debatable $[3,11]$. While there is an opinion that a linear relationship without a threshold exists between the Lp(a) levels and CVD outcomes among general populations [23], an Lp(a) of 30-50 mg/dl is often used as the cut-off level for CVD [24, 25]. The European guideline states that the desired $\mathrm{Lp}(\mathrm{a})$ level for the prevention of CVD is $<50 \mathrm{mg} / \mathrm{dl}$ for general populations and CVD subjects [26]. As most studies included in the current meta-analysis used cut-off levels of 50 or $60 \mathrm{mg} / \mathrm{dl}$ (as shown in Tables I and II), this might induce a somewhat high risk in $\mathrm{FH}$ subjects relative to general populations and generic/common hypercholesterolemic subjects $[5,11]$.

While LDL-C is a main target for the management in FH subjects, the current study findings suggest the need for attention to $L p(a)$ levels during management. Statins (HMG-CoA reductase inhibitors) are representative lipid-lowering drugs in hypercholesterolemic subjects, including FH subjects [27-29]. Therapies involving statins can increase or decrease $L p(a)$ levels [27-29]. Whether or not the statin effects influence the relative risk for CVD with $\mathrm{Lp}(\mathrm{a})$ in $\mathrm{FH}$ subjects is unclear. Recently, proprotein convertase subtilisin/kexin type 9 (PCSK9) inhibitors have been used to treat high LDL-C levels in conditions such as $\mathrm{FH}$, and these inhibitors reduce not only LDL-C but also Lp(a) levels [30]. The effect of reduction of $L p(a)$ by intervention with PCSK9 inhibitors on the relationship between $L p(a)$ and CVD should be explored in the future.

Several limitations associated with the current study warrant mention. First, there were not many studies included for the purpose of this topic. Second, confounding factors (e.g. obesity, hypertension) in the adjusted analysis were not fully unified across the studies.

In conclusion, the current meta-analysis revealed that $\mathrm{FH}$ subjects with high $\mathrm{Lp}(\mathrm{a})$ levels could have a high risk of CVD, and in addition to LDL-C, attention should be paid to $L p(a)$ levels in FH subjects.

\section{Conflict of interest}

The authors declare no conflict of interest.

\section{References}

1. Schmidt K, Noureen A, Kronenberg F, Utermann G. Structure, function, and genetics of lipoprotein (a). J Lipid Res 2016; 57: 1339-59.

2. Van Der Valk FM, Bekkering S, Kroon J, et al. Oxidized phospholipids on Lipoprotein(a) elicit arterial wall inflammation and an inflammatory monocyte response in humans. Circulation 2016; 134: 611-24.

3. Kotani K, Serban MC, Penson P, Lippi G, Banach M. Evidence-based assessment of lipoprotein(a) as a risk biomarker for cardiovascular diseases - some answers and still many questions. Crit Rev Clin Lab Sci 2016; 53: 370-8.

4. Nave AH, Lange KS, Leonards CO, et al. Lipoprotein (a) as a risk factor for ischemic stroke: a meta-analysis. Atherosclerosis 2015; 242: 496-503.

5. Genser B, Dias KC, Siekmeier R, Stojakovic T, Grammer T, Maerz W. Lipoprotein (a) and risk of cardiovascu- 
lar disease - a systematic review and meta analysis of prospective studies. Clin Lab 2011; 57: 143-56.

6. Feng Z, Li HL, Bei WJ, et al. Association of lipoprotein(a) with long-term mortality following coronary angiography or percutaneous coronary intervention. Clin Cardiol 2017; 40: 674-8.

7. Burgess S, Ference BA, Staley JR, et al. Association of LPA variants with risk of coronary disease and the implications for lipoprotein(a)-lowering therapies: a mendelian randomization analysis. JAMA Cardiol 2018; 3: 619-27.

8. Soutar AK, Naoumova RP. Mechanisms of disease: genetic causes of familial hypercholesterolemia. Nat Clin Pract Cardiovasc Med 2007; 4: 214-25.

9. Nordestgaard BG, Chapman MJ, Humphries SE, et al. Familial hypercholesterolaemia is underdiagnosed and undertreated in the general population: guidance for clinicians to prevent coronary heart disease Consensus Statement of the European Atherosclerosis Society. Eur Heart J 2013; 34: 3478-90.

10. Mabuchi H, Koizumi J, Shimizu M, Takeda R. Development of coronary heart disease in familial hypercholes terolemia. Circulation 1989; 79: 225-332.

11. Danik JS, Rifai N, Buring JE, Ridker PM. Lipoprotein(a), measured with an assay independent of apolipoprotein(a) isoform size, and risk of future cardiovascular events among initially healthy women. J Am Med Assoc 2006; 296: 1363-70

12. Afshar M, Pilote L, Dufresne L, Engert JC, Thanassoulis G. Lipoprotein(a) interactions with low-density lipoprotein cholesterol and other cardiovascular risk factors in premature acute coronary syndrome (ACS). J Am Heart Assoc 2016; 5: e003012.

13. Ellis KL, Pang J, Chieng D, et al. Elevated lipoprotein(a) and familial hypercholesterolemia in the coronary care unit: between Scylla and Charybdis. Clin Cardiol 2018; 41: 378-84.

14. Ellis KL, Pérez de Isla L, Alonso R, Fuentes F, Watts GF, Mata P. Value of measuring lipoprotein(a) during cascade testing for familial hypercholesterolemia. J Am Coll Cardiol 2019; 73: 1029-39.

15. Chan DC, Pang J, Hooper AJ, et al. Elevated lipoprotein(a), hypertension and renal insufficiency as predictors of coronary artery disease in patients with genetically confirmed heterozygous familial hypercholesterolemia. Int J Cardiol 2015; 201: 633-8.

16. Sun D, Zhou BY, Zhao X, et al. Lipoprotein(a) level associates with coronary artery disease rather than carotid lesions in patients with familial hypercholesterolemia. J Clin Lab Anal 2018; 32: e22442.

17. Jansen ACM, Van Aalst-Cohen ES, Tanck MW, et al. The contribution of classical risk factors to cardiovascular disease in familial hypercholesterolaemia: data in 2400 patients. J Intern Med 2004; 256: 482-90.

18. Holmes DT, Schick BA, Humphries KH, Frohlich J. Lipoprotein(a) is an independent risk factor for cardiovascular disease in heterozygous familial hypercholesterolemia. Clin Chem 2005; 51: 2067-73.

19. Allard MD, Saeedi R, Yousefi M, Frohlich J. Risk stratification of patients with familial hypercholesterolemia in a multi-ethnic cohort. Lipids Health Dis 2014; 13: 65.

20. Alonso R, Andres E, Mata N, et al. Lipoprotein(a) levels in familial hypercholesterolemia: an important predictor of cardiovascular disease independent of the type of LDL receptor mutation. J Am Coll Cardiol 2014; 63: 1982-9.

21. Pérez De Isla L, Alonso R, Mata N, et al. Predicting cardiovascular events in familial hypercholesterolemia: the
SAFEHEART registry (Spanish familial hypercholesterol emia cohort study). Circulation 2017; 135: 2133-44.

22. Cao YX, Jin JL, Guo YL, et al. Baseline and on-statin treat ment lipoprotein(a) levels for predicting cardiovascular events in patients with familial hypercholesterolemia. Atherosclerosis 2019; 291: 27-33.

23. Tipping RW, Ford CE, Simpson LM, et al. Lipoprotein(a) concentration and the risk of coronary heart disease, stroke, and nonvascular mortality. J Am Med Assoc 2009; 302: 412-23.

24. Kamstrup PR, Benn M, Tybjærg-Hansen A, Nordestgaard BG. Extreme lipoprotein(a) levels and risk of myocardial infarction in the general population: the Copenhagen city heart study. Circulation 2008; 117: 176-84.

25. Nago N, Kayaba K, Hiraoka J, et al. Lipoprotein(a) levels in the japanese population: Influence of age and sex, and relation to atherosclerotic risk factors: the Jichi Medical School cohort study. Am J Epidemiol 1995; 141: 815-21.

26. Nordestgaard BG, Chapman MJ, Ray K, et al. Lipopro tein(a) as a cardiovascular risk factor: current status. Eur Heart J 2010; 31: 2844-53.

27. Yeang C, Hung MY, Byun YS, et al. Effect of therapeutic interventions on oxidized phospholipids on apolipoprotein B100 and lipoprotein(a). J Clin Lipidol. 2016; 10: 594-603.

28. Takagi H, Umemoto T. Atorvastatin decreases lipoprotein(a): a meta-analysis of randomized trials. Int J Cardio 2012; 154: 183-6.

29. Tsimikas S, Gordts PLSM, Nora C, Yeang C, Witztum JL Statin therapy increases lipoprotein(a) levels. Eur Heart J 2020; 41: 2275-84.

30. Kotani K. Lipoprotein(a) in the advent of a PCSK9 world. Ann Clin Biochem 2020; 57: 102. 